\title{
Pengaruh Islamic Human Capital dan Pengembangan Karir terhadap Kinerja Karyawan Bank Syariah
}

\author{
Rahayu Ningsih \\ Magister Ekonomi Syariah Institut Agama Islam Negeri (LAIN) Bukittinggi \\ rahayu_n74@yahoo.com
}

\section{Asyari}

Fakultas Ekonomi dan Bisnis Islam

Institut Agama Islam Negeri (IAIN) Bukittinggi

asri_rara@yahoo.com

\section{Iiz Izmuddin}

Fakultas Ekonomi dan Bisnis Islam

Institut Agama Islam Negeri (LAIN) Bukittinggi

iizmudin@yahoo.com

\section{(c) (1) (2)}

(C)2020 by the authors. Submitted for possible open access publication under the terms and conditions of the Creative Commons Attribution (CC-BY-SA) license (https://creativecommons.org/licenses/by-sa/4.0/)

| DOI: http://dx.doi.org/10.30983/es.v4i2.3490

\begin{tabular}{l|l|l|} 
Diterima: 10 September 2020 & Direvisi: 30 November 2020 & Diterbitkan: 31 Desember 2020
\end{tabular}

\begin{abstract}
This study aims to measure the effect of Islamic Human Capital and career development on the performance of Islamic Bank employees in Pasaman district. This research was a causality research with a quantitative approach based on statistical data and empirical data at the research location. The population in this study were employees of Islamic Banks in Pasaman district. Sampling was carried out by total sampling, consisting of Bank Syariah Mandiri, Bank Syariah BTPN and Bank Nagari Syariah, as many as 32 people. Data were collected using questionnaires, observation and documentation. Based on the results of the data analysis, it appears that Islamic Human Capital has a positive effect on employee performance ( $p$-value $=0.000)$. While the career development variable does not have a positive and significant effect on employee performance $(p$-value $=0.589)$. Simultaneously, the Islamic Human Capital variable and career development have an effect on employee performance ( $p$-value $=0.000)$. The findings of this study reveal the importance of improving Islamic Human Capital and career development efforts in improving the performance of Islamic Bank employees, especially in Pasaman district
\end{abstract}

Keywords: Islamic Human Capital, Career Development, Employee Performance.

\section{Abstrak}

Penelitian ini bertujuan untuk mengukur pengaruh Islamic Human Capital dan pengembangan karir terhadap kinerja karyawan Bank Syariah di Kabupaten Pasaman. Penelitian ini merupakan penelitian kausalitas dengan pendekatan kuantitatif berdasarkan data statistik dan data empiris di lokasi penelitian. Populasi dalam penelitian ini adalah karyawan dari Bank Syariah yang terdapat di Kabupaten Pasaman. Penarikan sampel dilakukan dengan total sampling, yang terdiri dari Bank Syariah Mandiri, Bank Syariah BTPN dan Bank Nagari Syariah, sebanyak 32 orang. Teknik pengumpulan data adalah dengan metode kuesioner, observasi dan dokumentasi, Berdasarkan hasil analisis data terlihat bahwa Islamic Human Capital berpengaruh positif terhadap kinerja karyawan $(\mathrm{p}$-value $=0,000)$. Sedangkan variabel pengembangan karir tidak berpengaruh positif dan signifikan terhadap kinerja karyawan ( $\mathrm{p}-$ 
value $=0,589)$. Secara simultan, variabel Islamic Human Capital dan pengembangan karir berpengaruh terhadap kinerja karyawan $(\mathrm{p}$-value $=0.000)$. Temuan penelitian ini mengungkap pentingnya perbaikan Islamic Human Capital dan dan upaya pengembangan karir dalam meningkatkan kinerja karyawan Bank Syariah, terutama di kabupaten Pasaman.

\section{Kata Kunci: Islamic Human Capital, Pengembangan Karir, Kinerja Karyawan.}

\section{Latar Belakang}

Dalam perkembangannya perusahaan akan mengalami berbagai permasalahan sumber daya manusia. Oleh karena itu, sumber daya manusia harus dipimpin dan dikelola secara baik dan profesional.

Sumber Daya Insani (SDI) adalah salah satu faktor yang sangat penting bahkan tidak dapat dilepaskan dari sebuah organisas. ${ }^{2}$ Baik instansi maupun perusahaan. SDI juga merupakan kunci yang menentukan perkembangan perusahaan. Pada hakikatnya, SDI berupa manusia yang dipekerjakan di sebuah organisasi sebagai penggerak untuk mencapai tujuan organisasi itu.

Dewasa ini, perkembangan terbaru memandang karyawan bukan sebagai sumber daya belaka, melainkan lebih berupa modal atau aset bagi institusi atau organisasi. Disini SDM dilihat bukan sekedar aset utama, tetapi aset yang bernilai dan dapat dilipat gandakan, dapat dikembangkan dan juga bukan sebaliknya, sebagai beban atau cost. Jadi, Islamic Human Capital adalah sumber daya insani menurut Islam dan mempunyai sifat keislaman serta dapat menjunjung tinggi nilai keislaman.

Pengelolaan sumber daya secara profesional dimulai dari proses rekrutmen, seleksi, penempatan kerja, pelatihan sampai dengan pengembangan karir dan

1 Sudaryono, Pengantar Bisnis Teori Dan Contoh Kasus, (Jakarta: CV. Andi Offset, 2015).

2 Veithzal Rivai dan Deddy Mulyadi, 'Kepemimpinan Dan Perilaku Organisasi (Edisi Kedua)', Jakarta: PT. Raja Grafindo Ersada, 2008; Stephen P Robbins and Timothy A Judge, 'Perilaku Organisasi', Edisi Kesepuluh. Jakarta: PT Indeks Kelompok Gramedia, 2006; Alifiulahtin Utaminingsih, Perilaku Organisasi: Kajian Teoritik \& Empirik Terhadap Budaya Organisasi, Gaya Kepemimpinan, Kepercayaan Dan Komitmen (Universitas Brawijaya Press, 2014). kompensasinya. ${ }^{3}$ Dalam aktivitas sehari-hari manusia tidak terlepas dari aktivitas ekonomi. Adanya perbankan syariah menjadi solusi yang baik bagi masyarakat untuk melakukan tindakan ekonomi berdasarkan pada prinsip syariah. Seiring dengan berkembangnya zaman, banyak bermunculan bank yang awalnya berbasis konvensional berbondongbondong berubah menjadi bank dengan prinsip syariah. Akibat perkembangan industri perbankan syariah di Indonesia yang semakin meningkat, sehingga membutuhkan sumber daya manusia (SDM) yang profesional untuk menentukan laju pertumbuhan industri syariah kedepan. ${ }^{4}$

Kendala yang sering dijumpai mengenai sumber daya manusia antara lain minimnya pengalaman para pemimpin yang sulit menentukan standar proses rekruitmen, pihak perusahaan asal-asalan saja dalam merekrut karyawan sehingga banyak karyawan yang tidak berkompeten. Perusahaan lebih mengandalkan keterampilan dibandingkan latar belakang pendidikan dan pengalaman kerja padahal perusahaan perlu sumber daya manusia yang berkualitas agar bisa berkembang. ${ }^{5}$

Dalam bidang pengembangan kompetensi karyawan, seringkali pemilik usaha tidak memahami dengan tepat dimana potensi

3 Burhanuddin Yusuf dan M. Nuryanto Al-Arif, Manajemen Sumber Daya Manusia Di Lembaga Keuangan Syariah, (Jakarta: PT. Raja Grafindo Persada, 2015).

4 Abu Fahmi, Syariah: Teori Dan Implementasi (jakarta: PT. Gramedia Pustaka Utama, 2014).

${ }^{5} \mathrm{M}$ Arifin and Hesi Eka Puteri, 'Personality, Grit and Organizational Citizenship Behavior at Vocational Higher Education: The Mediating Role of Job Involvement', Journal of Social Studies Education Research, 10.2 (2019), 168-87; Yana Aisyah and Jaka Isgiyarta, 'Analisis Pengaruh Human Capital Terhadap Kualitas Auditor (Studi Empiris Pada Bank Bri Kantor Inspeksi Semarang)', Diponegoro Journal of Accounting, 3.2 (2014), 1038-47. 
karyawannya, hal itu terjadi karena tidak adanya komunikasi atau bidang yang tidak cocok, sehingga potensi karyawan tidak tampak. Manajemen sumber daya manusia berpengaruh terhadap potensi perusahaan yang akan dijalankan atau sedang dijalankan. Bila manajemen tertata dengan baik, tentu saja apa yang diharapkan akan tercapai. Oleh karena itu setiap pemimpin perusahaan perlu menguasai konsep dan teknik-teknik dalam proses pengelolaan sumber daya manusia yang Islami. Mulai proses rekrutmen, seleksi, pelatihan dan pengembangan, penilaian kinerja dan kompensasi. Dalam bank syariah yang ada di kabupaten pasaman, proses perekrutan dan seleksinya tidak mengedepankan latar belakang pendidikan dan pengalaman. Bahkan umumnya karyawan yang bekerja merupakan karyawan dengan berlatar pendidikan konvensional. Sedangkan banyak lulusan dari perguruan tinggi Islam yang tidak bekerja di Bank Syariah yang ada di Pasaman. Di bank syariah kabupaten Pasaman juga dilakukan pelatihan untuk para karyawan namun hal itu tidak cukup untuk memberikan pemahaman kepada karyawan mengenai prinsip-prinsip syariah. Dimana pada pelatihan lebih difokuskan pada cara untuk mengembangkan bisnis perusahaan sedangkan untuk pemahaman mengenai dasar-dasar prinsip syariah masih kurang.

Selain memperhatikan faktor buman capital untuk peningkatan kinerja karyawan, faktor kedua yang diidentifikasi mempengaruhi kinerja karyawan yaitu pengembangan karir. Pengembangan karir merupakan pendekatan formal yang dilakukan organisasi untuk menjamin orang-orang dalam organisasi mempunyai kualifikasi dan kemampuan serta pengalaman yang cocok ketika dibutuhkan. Agar karyawan dapat bekerja dengan lebih maksimal maka perusahaan perlu mengelola karir dan mengembangkannya dengan baik supaya produktivitas karyawan tetap terjaga dan mampu mendorong karyawan untuk melakukan hal yang terbaik sehingga berujung pada meningkatnya kinerja perusahaan dan tercapainya tujuan perusahaan. Dengan adanya pengembangan karir memungkinkan setiap karyawan mendapatkan kesempatan yang sama untuk memperoleh jabatan dan karir tertinggi.
Karyawan yang mempunyai kesempatan yang tinggi meningkatkan karirnya akan bekerja lebih baik. Hal ini tentu akan berpengaruh terhadap kinerja karyawan. Kinerja karyawan dapat bertahan dan meningkat tergantung pada perusahaan dalam memimpin karyawan dan mengelola pengembangan karir karyawannya. Meningkatnya kinerja karyawan dapat mempengaruhi peningkatan kinerja perusahaan dan tercapainya tujuan perusahaan.

\section{Rumusan Masalah}

Berdasarkan latar belakang masalah diatas, rumusan masalah yang akan dikaji dalam penelitian ini adalah, bagaimana pengaruh Islamic buman capital dan pengembangan karir terhadap kinerja karyawan, sebagai berikut:

1. Apakah terdapat pengaruh yang positif dan signifikan antara Islamic Human Capital terhadap kinerja karyawan Bank Syariah di Kabupaten Pasaman?

2. Apakah terdapat pengaruh yang positif dan signifikan antara pengembangan karir terhadap kinerja karyawan Bank Syariah di Kabupaten Pasaman?

3. Apakah terdapat pengaruh antara Islamic Human Capital dan pengembangan karir secara bersama-sama terhadap kinerja karyawan Bank Syariah di Kabupaten Pasaman?

\section{Tinjauan Pustaka}

Menurut Stewart et al mengatakan bahwa human capital merupakan lifeblood dalam intellectual capital, sumber dari innovation dan improvement, tetapi merupakan komponen yang sulit untuk diukur. ${ }^{6}$ Human capital mencerminkan kemampuan kolektif perusahaan untuk menghasilkan solusi terbaik berdasarkan pengetahuan yang dimiliki oleh orang-orang yang ada dalam perusahaan

${ }^{6}$ dan A. P. Kadir Sawarjuwono, T., 'Intellectual Capital: Perlakuan, Pengukuran Dan Pelaporan. Jurnal Akuntansi Dan Keuangan', Jurnal Akuntansi Dan Keuangan, v01.5 (2003), 35-57; Tasawar Nawaz, 'Intellectual Capital, Financial Crisis and Performance of Islamic Banks: Does Shariah Governance Matter?', International Journal of Business and Society, 18.1 (2017), 211-26; Richard Petty and James Guthrie, 'Intellectual Capital Literature Review', Journal of Intellectual Capital, 2000 .
Analisis Pengaruh Islamic.... 
tersebut, dimana akan meningkat jika perusahaan mampu menggunakan pengetahuan yang dimiliki oleh karyawannya.

Perkembangan terbaru memandang karyawan bukan sebagai sumber daya belaka, melainkan lebih berupa modal atau aset bagi institusi atau organisasi. Karena itu kemudian muncullah istilah baru di luar H.R. (Human Resources), yaitu H.C. atau Human Capital. Di sini SDM dilihat bukan sekadar sebagai aset utama, tetapi aset yang bernilai dan dapat dilipat gandakan, dikembangkan (bandingkan dengan portofolio investasi) dan juga bukan sebaliknya sebagai liability (beban,cost). Di sini perspektif SDI sebagai investasi bagi institusi atau organisasi lebih mengemuka.

Sumber Daya Insani adalah salah satu faktor yang sangat penting bahkan tidak dapat dilepaskan dari sebuah organisasi. ${ }^{7}$

Pengertian SDI dapat dibagi menjadi dua, yaitu pengertian mikro dan makro. Pengertian SDI secara mikro adalah individu yang bekerja dan menjadi anggota suatu perusahaan atau institusi dan biasa disebut sebagai pegawai, buruh, karyawan, pekerja, tenaga kerja dan lain sebagainya. Sedangkan pengertian SDI secara makro adalah penduduk suatu negara yang sudah memasuki usia angkatan kerja, baik yang belum bekerja maupun yang sudah bekerja. Secara garis besar, pengertian Sumber Daya Insani adalah individu yang bekerja sebagai penggerak suatu organisasi, baik instansi maupun perusahaan dan berfungsi sebagai aset yang harus dilatih dan dikembangkan kemampuannya. Islamic Human Capital adalah sumber daya insani menurut islam dan mempunyai sifat keislaman serta dapat menjunjung tinggi nilai keIslaman. Dengan pengelolaan Islamic Human Capital yang baik, dapat menciptakan lingkungan kerja yang harmonis, membantu dalam penempatan sumber daya insani sesuai dengan kemampuan dan keahliannya akan dapat meningkatkan kinerja perusahaan. Menurut Nugraha dan Aini (2018) kemampuan individu yang dimiliki oleh setiap modal manusia dari perusahaan apabila diolah menjadi lebih baik akan mendapatkan keuntungan yang positif

\footnotetext{
Organisasi.
}

terhadap perusahaan. Rahmat dan Agusti juga menyatakan dalam penelitiannya bahwa sejarah, nilai dan benturan memperlihatkan bahwa pentingnya membangun kebijakan SDM dimulai dari manajer senior yang memiliki sifat alim bukan hanya sekedar paham, tetapi juga menjiwai agama. Agar dapat menutup kesenjangan antara aturan teks dengan tataran praktik.

Sebuah perusahaan akan menghasilkan kinerja yang berbeda jika dikelola oleh orang yang berbeda, oleh karena itu, SDM yang berbeda dalam mengelola aset perusahaan yang sama akan menghasilkan nilai tambah yang berbeda pula. ${ }^{8}$ Dapat disimpulkan bahwa tangible aset yang dimiliki perusahaan bersifat pasif tanpa sumber daya manusia yang dapat mengelola dan menciptakan nilai bagi suatu perusahaan. Beberapa penelitian terakhir telah membuktikan keterkaitan antara kinerja karyawan dengan proses pengelolaan SDM di perusahaan.

Pengembangan karir organisasional merupakan hasil-hasil yang muncul dari interaksi antara perencanaan karir individu dengan manajemen karir secara institusional. Pengembangan karir adalah suatu kondisi yang menunjukan adanya peningkatan jenjang atau status seseorang dalam pekerjaannya sehingga dapat memenuhi kebutuhan, hal ini didorong melalui penilaian kepribadian dan latar belakang pendidikan. Pada umumnya tujuan dari seluruh pengembangan karir adalah untuk menyesuaikan antara kebutuhan dan tujuan karyawan dengan kesempatan yang tersedia di perusahaan saat ini dan di masa mendatang. Banyak orang gagal mengelola karir mereka, karena mereka tidak memperhatikan konsepkonsep dasar perencanaan karir. Mereka tidak menyadari sasaran-sasaran karir dapat memacu karir mereka dan menghasilkan sukses yang lebih besar. 9 Pengembangan karir adalah kegiatan-kegiatan pengembangan diri yang ditempuh oleh seseorang untuk mewujudkan

8 c totanan, 'Peranan Intellectual Capital Dalam Penciptaan Nilai Untuk Keunggulan Bersaing.', in N0.1, 2004, pp. 27-31.

9 Hani Handoko, Manajemen Personalia Dan Sumber Daya Manusia, edisi 2 (Yogyakarta: BPFE, 2014). 
rencana karir pribadinya. 1011 Sebuah pendekatan formal yang dilakukan organisasi untuk memastikan bahwa orang dengan kualifikasi dan pengalaman yang tepat akan bersedia pada saat dibutuhkan. ${ }^{12}$ Dalam penelitian Parerung (2014) menunjukkan bahwa pengembangan karir berpengaruh terhadap kinerja karyawan. Hal ini menunjukkan dengan adanya pengembangan karir, karyawan merasa adanya kepastian dalam karir yang akan diraih di masa yang akan datang, sehingga diimbangi dengan memberikan kinerja yang optimal. ${ }^{13}$

Kinerja adalah pelaksanaan suatu pekerjaan dan penyempurnaan pekerjaan tersebut sesuai dengan tanggung jawabnya sehingga dapat mencapai hasil sesuai dengan yang diharapkan ${ }^{14}$. Menurut Rivai (2005) kinerja adalah hasil atau tingkat keberhasilan seseorang atau keseluruhan dalam suatu periode tertentu di dalam melaksanakan tugas dibandingkan dengan berbagai kemungkinan, seperti standar hasil kerja, target atau sasaran atau kriteria yang telah ditentukan terlebih dahulu dan telah disepakati bersama. ${ }^{15}$ Menurut Hersey dan Blanchard (1993) kinerja

10 Hesi Eka Puteri and M Arifin, 'Exploring Personality , Grit and Organizational Citizenship Behavior at Higher Education : The Mediating Roles Of Job Involvement Exploring Personality , Grit, and Organizational Citizenship Behavior at Higher Education: The Mediating Roles Of Job Involve', Journal of Physics: Conference Series, 1471.1 (2020), 12025 $<$ https://doi.org/10.1088/1742-

6596/1471/1/012025>; Abrian Imanuel Kojo, Paulus Kindangen, and Yantje Uhing, 'Pengaruh Manajemen Perubahan, Budaya Organisasi Dan Keterlibatan Kerja Terhadap Kinerja Pada PT. Bank Sulut Go', Jurnal EMBA: Jurnal Riset Ekonomi, Manajemen, Bisnis Dan Akuntansi, 7.3 (2019); Suchuan Zhang, 'Impact of Job Involvement on Organizational Citizenship Behaviors in China', J Bus Ethics, 120, 2014, 165-74 <https://doi.org/10.1007/s10551-013-1654-x>.

${ }^{11}$ Puteri and Arifin.

12 marwansyah, Manajemen Sumber Daya Manusia Edisi 2. Bandung: Alfabeta, 2010) (Bandung: Alfabeta, 2010).

13 A Parerung, 'Disiplin, Kompensasi Dan Pengembangan Karir Pengaruhnya Terhadap Kinerja Pada Badan Lingkungan Hidup Provinsi Sulawesi Selatan', EMBA, 2.4 (2014).

14 Lijan P Sinambela, Kinerja Pegawai Teori Pengukuran Dan Implikasi (Yogyakarta: Graha Ilmu, 2012).

$$
{ }^{15} \text { Sinambela. }
$$

Rahayu Ningsih merupakan suatu fungsi dari motivasi dan kemampuan untuk menyelesaikan tugas dan pekerjaan, seseorang harus memiliki derajat kesediaan dan tingkat kemampuan tertentu. ${ }^{16}$ Kesediaan dan keterampilan seseorang tidaklah cukup efektif untuk mengerjakan sesuatu tanpa pemahaman yang jelas tentang apa yang akan dikerjakan dan bagaimana mengerjakannya. Kinerja adalah hasil yang diperoleh oleh suatu organisasi baik organisasi tersebut bersifat profit oriented dan non profit oriented yang dihasilkan selama satu periode waktu tertentu. ${ }^{17}$ Kinerja merupakan hasil pekerjaan yang mempunyai hubungan kuat dengan tujuan strategis organisasi, kepuasan konsumen dan memberikan kontribusi ekonomi. ${ }^{18}$

Dalam penelitian kuantitatif, kerangka berpikir merupakan model konseptual tentang bagaimana teori berhubungan dengan berbagai faktor yang telah diidentifikasi sebagai masalah yang penting. Kerangka pemikiran dalam penelitian ini sebagai berikut:

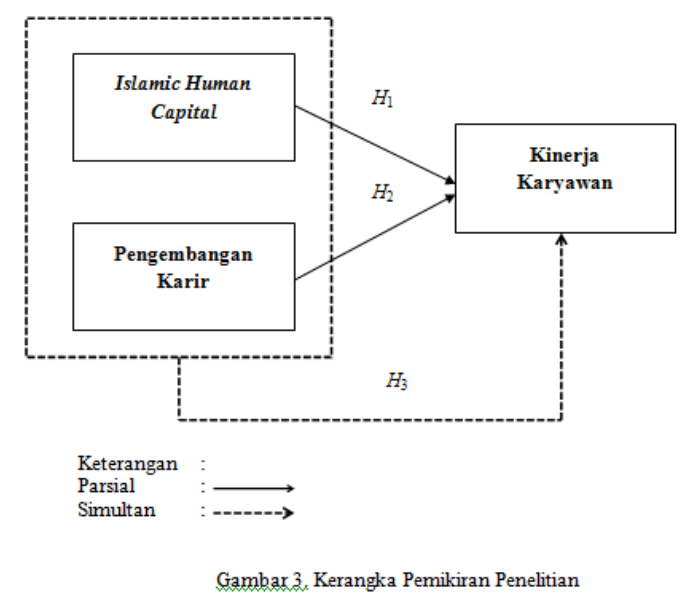

Hipotesis adalah jawaban sementara dari suatu penelitian karena dari hasil

16 Sinambela; Nasfi Nasfi, Rahmad Rahmad, and Sabri Sabri, 'Pengaruh Kualitas Pelayanan Terhadap Kepuasan Nasabah Perbankan Syariah', EKONOMIKA SYARIAH: Journal of Economic Studies, 4.1 (2020), 19-38.

17 Irham Fahmi, Manajemen Kinerja (Bandung: Alfabet, 2010).

18 Michael. Amstrong and Angela Baron, Performance Management, Performance Management. London: Institute of Personnel and Development (London: Institute of Personnel and Development., 1998); Fahmi; Sri Langgeng Ratnasari, M M SE, and Yenni Hartati, Manajemen Kinerja Dalam Organisasi (Penerbit Qiara Media, 2019).

Analisis Pengaruh Islamic.... 
pengujian hipotesis merupakan jawaban dari masalah yang ditemukan. Berdasarkan landasan teori, penelitian yang relevan dan kerangka berpikir, maka hipotesis yang dikemukakan dalam penelitian ini adalah:

Hipotesis $1\left(H_{1}\right)$ : Terdapat pengaruh yang positif dan signifikan antara Islamic Human Capital dan kinerja karyawan.

Hipotesis $2\left(\mathrm{H}_{2}\right)$ : Terdapat pengaruh yang positif dan signifikan antara pengembangan karir dan kinerja karyawan.

Hipotesis $3\left(H_{3}\right)$ : Terdapat pengaruh yang positif dan signifikan antara Islamic Human Capital dan pengembangan karir secara bersama-sama dengan kinerja karyawan.

\section{Metode Penelitian}

Jenis penelitian ini adalah penelitian kausalitas yang menganalisis hubungan sebab akibat (pengaruh) antar variabel dalam penelitian ini. Penelitian kausalitas adalah penelitian yang menunjukkan arah hubungan variabel bebas dengan variabel terikat, disamping mengukur kekuatan hubungannya. ${ }^{19}$

${ }^{20}$ Metode penelitian yang digunakan dalam penelitian ini adalah metode kuantitatif berdasarkan data statistik dan empiris.

Tempat penelitian dilakukan di Bank Syariah (Bank Syariah Mandiri, Bank Syariah BTPN, dan Bank Nagari Syariah) yang terdapat di Kabupaten Pasaman Provinsi Sumatera Barat. Waktu penelitian dilakukan pada bulan Oktober 2019.

Populasi dalam penelitian ini adalah karyawan dari Bank Syariah yang terdapat di Kabupaten Pasaman Provinsi Sumatera Barat. Penarikan sampel dilakukan dengan Total Sampling terhadap karyawan Bank Syariah di Kabupaten Pasaman. Karena jumlah karyawan Bank Syariah di Kabupaten Pasaman yang terdiri dari Bank Syariah Mandiri, Bank Syariah

${ }^{19}$ Kuncoro Mudrajad, 'Metode Riset Untuk Bisnis Dan Ekonomi', Jakarta: Erlangga, 2003; Dr. Juliansyah Noor, 'Metodologi Penelitian: Skripsi, Tesis, Disertasi, \& Karya Ilmiah', in Metodologi Penelitian: Skripsi, Tesis, Disertasi, \& Karya Ilmiah, 2011; Didin Fatihudin, 'Metodologi Penelitian Untuk Ilmu Ekonomi, Manajemen Dan Akuntansi: Dari Teori Ke Praktek' (Zifatama Publishing, 2015).

${ }^{20}$ kuncoro Mudrajad, Metode Riset Untuk Bisnis Dan Ekonomi, edisi 4 (jakarta: erlangga).
BTPN dan Bank Nagari Syariah adalah sebanyak 32 orang, maka seluruh karyawan dijadikan sampel dalam penelitian ini.

Dalam penelitian ini teknik pengumpulan data yang digunakan adalah metode kuesioner (angket), observasi dokumen dan wawancara. Teknik pengujian instrumen dalam penelitian ini dilakukan dengan uji validitas dan reliabilitas. Pengujian hipotesis dengan menggunakan uji t (secara parsial) dan uji $\mathrm{F}$ (secara simultan).

Variabel bebas dalam penelitian ini adalah Islamic buman capital (X1) dan pengembangan karir (X2). Sedangkan variabel terikat dalam penelitian ini adalah kinerja karyawan $(\mathrm{Y})$.

Pengukuran variabel dalam penelitian ini menggunakan skala Likert dimulai dari skor 1 Sangat Tidak Setuju (STS), skor 2 Tidak Setuju (TS), skor 3 Netral (N), skor 4 Setuju (S) dan skor 5 Sangat Setuju (ST)

Tabel 1. Definisi Operasional

\begin{tabular}{|c|c|c|}
\hline $\begin{array}{l}\text { Variabel } \\
\text { penelitian }\end{array}$ & Definisi & Indikator \\
\hline $\begin{array}{l}\text { Islamic } \\
\text { Human } \\
\text { Capital } \\
\text { (X1) }\end{array}$ & $\begin{array}{l}\text { Islamic Human } \\
\text { Capital } \\
\text { merupakan } \\
\text { perwujudan } \\
\text { dari konsep } \\
\text { manusia } \\
\text { sebagai di } \\
\text { khalifah di } \\
\text { muka bumi } \\
\text { ini yang } \\
\text { berpotensi } \\
\text { besar dalam } \\
\text { menentukan } \\
\text { nilai suatu } \\
\text { peradaban } \\
\text { atau suasana } \\
\text { kehidupan. } \\
\text { Melalui } \\
\text { konsep } \\
\text { tersebut } \\
\text { manusia telah } \\
\text { diposisikan } \\
\text { sebagai } \\
\text { subjek } \\
\text { sekaligus } \\
\text { objek, yaitu } \\
\text { sebagai } \\
\text { sumber daya }\end{array}$ & $\begin{array}{l}\text { 1. Kemanusia } \\
\text { an } \\
\text { 2. Demokrasi } \\
\text { 3. The Right } \\
\text { Man is The } \\
\text { Right Place } \\
\text { 4. Equal Pay } \\
\text { for Equal } \\
\text { Work } \\
\text { 5. Kesatuan } \\
\text { Arah } \\
\text { 6. Kesatuan } \\
\text { Komando } \\
\text { 7. Efisiensi } \\
\text { 8. Efektivitas } \\
\text { 9. Produktivit } \\
\text { as Kerja } \\
\text { 10. Disiplin } \\
\text { 11. Wewenang } \\
\text { dan } \\
\text { Tanggung } \\
\text { Jawab } \\
\text { (Rivai, 2014) }\end{array}$ \\
\hline
\end{tabular}

Analisis Pengaruh Islamic.... 


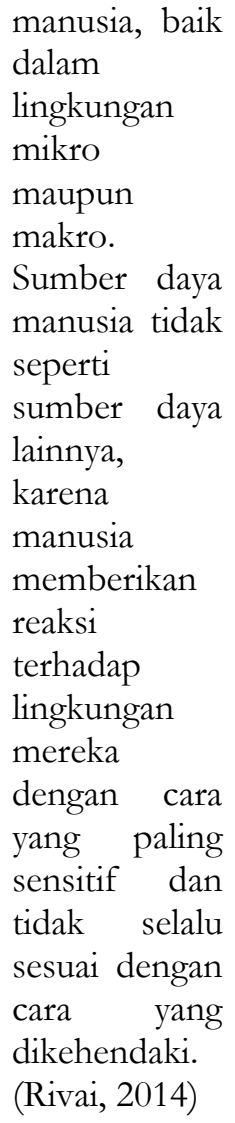

\begin{tabular}{|c|c|c|}
\hline $\begin{array}{l}\text { Pengemba } \\
\text { ngan Karir } \\
\text { (X2) }\end{array}$ & $\begin{array}{l}\text { Pengembanga } \\
\mathrm{n} \text { Karir } \\
\text { adalah } \\
\text { kegiatan- } \\
\text { kegiatan } \\
\text { pengembanga } \\
\text { n diri yang } \\
\text { ditempuh } \\
\text { oleh } \\
\text { seseorang } \\
\text { untuk } \\
\text { mewujudkan } \\
\text { rencana karir } \\
\text { pribadinya. } \\
\text { Sebuah } \\
\text { pendekatan } \\
\text { formal yang } \\
\text { dilakukan } \\
\text { organisasi } \\
\text { untuk } \\
\text { memastikan } \\
\text { bahwa orang } \\
\text { dengan } \\
\text { kualifikasi } \\
\text { dan } \\
\text { pengalaman } \\
\text { yang tepat } \\
\text { akan bersedia } \\
\text { pada }\end{array}$ & $\begin{array}{l}\text { 1. Kebijakan } \\
\text { organisasi } \\
\text { 2. Prestasi } \\
\text { kerja } \\
\text { 3. Latar } \\
\text { belakang } \\
\text { pendidikan } \\
\text { 4. Pelatihan } \\
\text { 5. Pengalama } \\
\text { n kerja } \\
\text { Kesetiaan } \\
\text { pada } \\
\text { organisasi } \\
\text { Sihotang (2006) } \\
\text { (dalam } \\
\text { Batubara, } \\
\text { 2016:13) }\end{array}$ \\
\hline
\end{tabular}

dibutuhkan

(Marwansyah, 2009:208).

\begin{tabular}{|c|c|c|}
\hline $\begin{array}{l}\text { Kinerja } \\
\text { Karyawan } \\
\text { (Y) }\end{array}$ & $\begin{array}{l}\text { Kinerja SDM } \\
\text { adalah } \\
\text { prestasi kerja } \\
\text { atau hasil } \\
\text { kerja (output) } \\
\text { baik kualitas } \\
\text { maupun } \\
\text { kuantitas yang } \\
\text { dicapai SDM } \\
\text { persatuan } \\
\text { periode waktu } \\
\text { dalam } \\
\text { melaksanakan } \\
\text { tugas kerjanya } \\
\text { sesuai dengan } \\
\text { tanggung } \\
\text { jawab yang } \\
\text { diberikan } \\
\text { kepadanya } \\
\text { (Mangkunega } \\
\text { ra, 2005:9). }\end{array}$ & $\begin{array}{l}\text { 1. Kualitas } \\
\text { kerja } \\
\text { 2. Kuantitas } \\
\text { kerja } \\
\text { 3. Ketepatan } \\
\text { waktu } \\
\text { 4. Efektivitas } \\
\text { 5. Kemandiria } \\
\quad \mathrm{n} \\
\text { 6. Komitmen } \\
\text { (Bernadin } \\
\text { dalam Ardianto, } \\
\text { 2005:20). }\end{array}$ \\
\hline
\end{tabular}




\section{Hasil dan Pembahasan}

Data Responden

Dari data yang diperoleh telah diklasifikasikan mengenai data responden sebagai berikut:

\section{Tabel 1}

\section{Data Responden}

\begin{tabular}{|c|c|c|}
\hline Kategori & Responden & Persentase \\
\hline \multicolumn{3}{|c|}{ Jenis Kelamin } \\
\hline Pria & 17orang & $53 \%$ \\
\hline \multirow[t]{2}{*}{ Wanita } & 15orang & $47 \%$ \\
\hline & 32 orang & $100 \%$ \\
\hline \multicolumn{3}{|l|}{ Usia } \\
\hline$<20$ tahun & 0orang & $0 \%$ \\
\hline 20-30 tahun & 24orang & $75 \%$ \\
\hline 31-40 tahun & 7orang & $22 \%$ \\
\hline \multirow[t]{2}{*}{$>40$ tahun } & 1orang & $3 \%$ \\
\hline & 32 orang & $100 \%$ \\
\hline \multicolumn{3}{|c|}{ Pendidikan Terakhir } \\
\hline $\begin{array}{l}\text { SMA } \\
\text { Sederajat }\end{array}$ & 7orang & $22 \%$ \\
\hline D3 & 3orang & $9 \%$ \\
\hline S1 & 22orang & $69 \%$ \\
\hline S2 & Oorang & $0 \%$ \\
\hline \multirow[t]{2}{*}{ S3 } & Oorang & $0 \%$ \\
\hline & 32 orang & $100 \%$ \\
\hline \multicolumn{3}{|c|}{ Lama Bekerja } \\
\hline$<1$ tahun & 0orang & $0 \%$ \\
\hline 1-3 tahun & 12orang & $38 \%$ \\
\hline 4-5 tahun & 10orang & $31 \%$ \\
\hline$>5$ tahun & 10orang & $31 \%$ \\
\hline
\end{tabular}

Sumber: Data primer yang telah diolah, 2019

\section{Uji Validitas}

Berikut ini adalah hasil perhitungan validitas yang dijelaskan per variabel, yaitu:

\section{Islamic Human Capital}

Adapun dalam variabel islamic buman capital terdapat 11 pernyataan yang akan diuji validitas, berikut hasil uji validitas variabel islamic buman capital, yaitu:

Tabel 2

Hasil Uji Validitas Variabel Islamic Human Capital

\begin{tabular}{lllll}
\hline Variabel & $\begin{array}{l}\text { No } \\
\text { Item }\end{array}$ & $\mathbf{r}_{\text {hitung }}$ & $\mathbf{r}_{\text {tabel }}$ & Ket \\
\hline & IHC1 & 0,408 & 0,361 & Valid \\
\cline { 2 - 5 } & IHC2 & 0,547 & 0,361 & Valid \\
\cline { 2 - 5 } & IHC3 & 0,455 & 0,361 & Valid \\
\cline { 2 - 5 } Islamic & IHC4 & 0,600 & 0,361 & Valid \\
\cline { 2 - 5 } Caman & IHC5 & 0,682 & 0,361 & Valid \\
\cline { 2 - 5 } & IHC6 & 0,639 & 0,361 & Valid \\
\cline { 2 - 5 } & IHC7 & 0,489 & 0,361 & Valid \\
\cline { 2 - 5 } & IHC8 & 0,581 & 0,361 & Valid \\
\cline { 2 - 5 } & IHC9 & 0,725 & 0,361 & Valid \\
\cline { 2 - 5 } & IHC10 & 0,556 & 0,361 & Valid \\
\cline { 2 - 5 } & IHC11 & 0,517 & 0,361 & Valid \\
\hline
\end{tabular}

Sumber: Data Primer yang telah diolah, 2019

Berdasarkan tabel di atas ditemukan bahwa seluruh pernyataan pada variabel Islamic Human Capital memiliki nilai Rhitung $>$ Rtabel yang dinyatakan seluruh pernyataan valid, maka pertanyaan dianggap layak sebagai penelitian dapat dilanjutkan pada tahap selanjutnya.

\section{Pengembangan Karir}

Adapun dalam variabel pengembangan karir terdapat 6 pernyataan yang akan diuji validitas, berikut hasil uji validitas variabel pengembangan karir, yaitu: 
Tabel 3

Hasil Uji Validitas Variabel Pengembangan Karir

\begin{tabular}{lllll}
\hline Variabel & $\begin{array}{l}\text { No } \\
\text { Item }\end{array}$ & $\mathbf{r}_{\text {hitung }}$ & $\mathbf{r}_{\text {tabel }}$ & Ket \\
\hline \multirow{4}{*}{$\begin{array}{l}\text { Pengem } \\
\text { bangan }\end{array}$} & PK1 & 0,786 & 0,361 & Valid \\
\cline { 2 - 5 } Karir & PK2 & 0,861 & 0,361 & Valid \\
\cline { 2 - 5 } & PK3 & 0,915 & 0,361 & Valid \\
\cline { 2 - 5 } & PK4 & 0,641 & 0,361 & Valid \\
\cline { 2 - 5 } & PK5 & 0,510 & 0,361 & Valid \\
\hline
\end{tabular}

Sumber: Data Primer yang telah diolah, 2019

Berdasarkan tabel di atas ditemukan bahwa seluruh pernyataan pada variabel pengembangan karir memiliki nilTabel 5

Rhitung $>$ Rtabel yang dinyatakan seluruh pernyataan valid, maka pertanyaan dianggap layak sebagai penelitian dapat dilanjutkan pada tahap selanjutnya.

\section{Kinerja Karyawan}

Adapun dalam variabel kinerja karyawan terdapat 6 pernyataan yang akan diuji validitas, berikut hasil uji validitas variabel pengembangan karir, yaitu:

\section{Tabel 4}

Hasil Uji Validitas Variabel Kinerja Karyawan

\begin{tabular}{|c|c|c|c|c|}
\hline Variabel & $\begin{array}{l}\text { No } \\
\text { Item }\end{array}$ & $\mathbf{r}_{\text {hitung }}$ & $\mathbf{r}_{\text {tabel }}$ & $\begin{array}{l}\text { Ketera } \\
\text { ngan }\end{array}$ \\
\hline \multirow{6}{*}{$\begin{array}{l}\text { Kinerja } \\
\text { Karyawan }\end{array}$} & KK1 & $\begin{array}{l}0,73 \\
1\end{array}$ & 0,361 & Valid \\
\hline & KK2 & $\begin{array}{l}0,75 \\
7\end{array}$ & 0,361 & Valid \\
\hline & KK3 & $\begin{array}{l}0,74 \\
5 \\
\end{array}$ & 0,361 & Valid \\
\hline & KK4 & $\begin{array}{l}0,68 \\
2\end{array}$ & 0,361 & Valid \\
\hline & KK5 & $\begin{array}{l}0,63 \\
9\end{array}$ & 0,361 & Valid \\
\hline & KK6 & $\begin{array}{l}0,69 \\
6\end{array}$ & 0,361 & Valid \\
\hline
\end{tabular}

Sumber: Data Primer yang telah diolah, 2019

Berdasarkan tabel di atas ditemukan bahwa seluruh pernyataan pada variabel kinerja karyawan memiliki nilai Rhitung $>$ Rtabel yang dinyatakan seluruh pernyataan valid, maka pertanyaan dianggap layak sebagai penelitian dapat dilanjutkan pada tahap selanjutnya.

\section{Uji Reliabilitas}

Hasil uji reliabilitas ini dilakukan dengan menggunakan Cronbach Alpha.Suatu variabel dapat dikatakan reliabel jika Cronbach Alpha $>0,60 .^{21}$ Berikut ini adalah hasil perhitungan reliabilitas yang dijelaskan per variabel, yaitu:

\section{Islamic Human Capital}

Adapun dalam variabel ini terdapat 11 pernyataan yang akan diuji reliabilitas, berikut uji reliabilitas variabel islamic human capital, yaitu:

Hasil Uji Reliabilitas Variabel Islamic Human Capital

\begin{tabular}{ll}
\hline Croncbach's Alpha & N of Items \\
\hline 0,776 & 11 \\
\hline Sumber: Data Primer & 11 .
\end{tabular}

Sumber: Data Primer yang telah diolah, 2019

Berdasarkan tabel hasil Uji reliabilitas Islamic human capital diatas, dapat disimpulkan bahwa butir kuesioner variabel Islamic buman capital dapat dikatakan reliabel karena nilai dari Cronbach's Alpha dari variabel Islamic buman capital yaitu $0,776>0,60$. Maka jawaban responden dianggap layak sebagai penelitian dapat dilanjutkan pada tahap selanjutnya.

\section{Pengembangan Karir}

Adapun dalam variabel ini terdapat 6 pernyataan yang akan diuji reliabilitas, berikut uji reliabilitas variabel pengembangan karir, yaitu:

Tabel 6

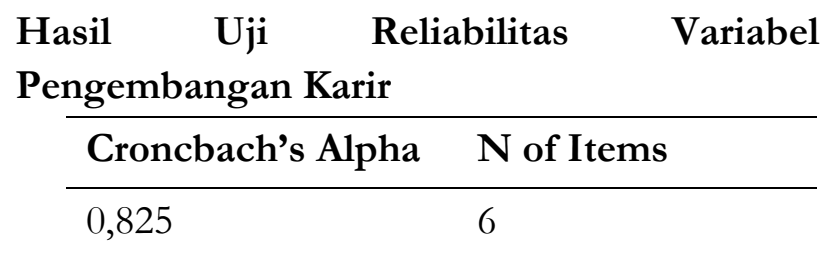

Sumber: Data Primer yang telah diolah, 2019

Berdasarkan tabel hasil Uji reliabilitas pengembangan karir diatas, dapat disimpulkan bahwa butir kuesioner variabel pengembangan

21 Suharsimi Arikunto, Prosedur Penelitian Ilmiah (Jakarta: Rineka Cipta, 2010).

Analisis Pengaruh Islamic.... 
karir dapat dikatakan reliabel karena nilai dari Cronbach's Alpha dari variabel pengembangan karir yaitu 0,825 > 0,60. Maka jawaban responden dianggap layak sebagai penelitian dapat dilanjutkan pada tahap selanjutnya.

\section{Kinerja Karyawan}

Adapun dalam variabel ini terdapat 6 pernyataan yang akan diuji reliabilitas, berikut uji reliabilitas variabel kinerja karyawan, yaitu:

\section{Tabel 7}

Hasil Uji Reliabilitas Variabel Kinerja Karyawan

\begin{tabular}{ll}
\hline Croncbach's Alpha & N of Items \\
\hline 0,765 & 6
\end{tabular}

Sumber: Data Primer yang telah diolah, 2019

Berdasarkan tabel hasil Uji reliabilitas kinerja karyawan diatas, dapat disimpulkan bahwa butir kuesioner variabel kinerja karyawan dapat dikatakan reliabel karena nilai dari Cronbach's Alpha dari variabel kinerja karyawan yaitu 0,765 > 0,60. Maka jawaban responden dianggap layak sebagai penelitian dapat dilanjutkan pada tahap selanjutnya.

\section{Uji Normalitas}

Pengujian ini dilakukan untuk mengetahui bahwa distribusi penyampaian data yang digunakan telah terdistribusi secara normal.Uji ini dilakukan dengan uji One-Sample Kolmogorov - Smirnov Test. Data dinyatakan berdistribusi normal jika Asymp. Sig. (2-tailed) $>0,05$. Berikut ini adalah hasil uji normalitas.

\section{Tabel 8}

\section{Uji Normalitas Kolmogorov-Smirnov Test}

\begin{tabular}{|ll|r|}
\hline \multicolumn{2}{|c|}{ One-Sample Kolmogorov-Smirnov Test } \\
\hline N & $\begin{array}{r}\text { Unstandardiz } \\
\text { ed Residual }\end{array}$ \\
\hline Normal Parameters s.b & Mean & 32 \\
& Std. Deviation &, 0000000 \\
Most Extreme & Absolute & 2,32427911 \\
Differences & Positive &, 126 \\
& Negative &, 126 \\
Kolmogorov-Smirnov Z & &,- 078 \\
Asymp. Sig. (2-tailed) & &, 713 \\
\hline
\end{tabular}

Sumber: Data diolah dengan SPSS, 2019
Berdasarkan tabel di atas, hasil asymp.sig sebesar 0,689 dengan nilai signifikansi jauh di atas $0,05(0,689>0,05)$ yang berarti nilai residual terdistribusi secara normal atau memenuhi asumsi klasik.

\section{Uji Heteroskedastisitas}

Uji heteroskedastisitas bertujuan untuk menguji apakah pada model regresi terjadi ketidaksamaan variance dari residual satu pengamatan ke pengamatan lain. Metode yang digunakan adalah metode chart, dimana jika ada pola yang jelas, serta titik menyebar keatas dan di bawah 0 pada sumbu $Y$, maka tidak terjadi Heteroskedastisitas. ${ }^{22}$

\section{Tabel 9}

\section{Hasil Uji Heteroskedastisitas}

\begin{tabular}{|c|c|c|c|c|c|c|}
\hline \multirow[b]{2}{*}{ Model } & & \multicolumn{2}{|c|}{$\begin{array}{l}\text { Unstandardized } \\
\text { Coefficients }\end{array}$} & \multirow{2}{*}{$\begin{array}{c}\text { Standardized } \\
\text { Coefficients } \\
\text { Beta }\end{array}$} & \multirow[b]{2}{*}{$t$} & \multirow[b]{2}{*}{ Sig. } \\
\hline & & $B$ & Sto. Error & & & \\
\hline \multirow[t]{3}{*}{1} & (Constant) & 1,774 & 3,414 & & 519 & 607 \\
\hline & $\begin{array}{l}\text { Islamic_Human_Capital } \\
\text { (X1) }\end{array}$ & .029 & 078 & -075 & -370 &, 714 \\
\hline & $\begin{array}{l}\text { Pengembannan__karir } \\
\left(X_{2}\right)\end{array}$ & ,052 & 081 & 129 & .638 & .528 \\
\hline
\end{tabular}

Sumber: Data diolah dengan SPSS, 2019

Berdasarkan tabel diatas diketahui nilai signifikansi (Sig) untuk variabel Islamic Human Capital (X1) adalah 0,714. Sementara, nilai signifikansi (Sig) untuk variabel Pengembangan Karir (X2) adalah 0,528. Maka nilai signifikansi (Sig) untuk variabel Islamic Human Capital (X1) 0,714 > 0,05 dan nilai signifikansi (Sig) untuk variabel Pengembangan Karir (X2) 0,528 > 0,05, sesuai dengan dasar pengambilan keputusan dalam uji gletjser, dapat disimpulkan bahwa tidak terjadi gejala heteroskedastisitas dalam model regresi dan hasil uji dapat dilanjutkan.

\section{Uji Multikolinearitas}

Model regresi yang baik seharusnya tidak terjadi korelasi di antara variabel independen. ${ }^{23}$

22 Muhammad Firdaus, Ekonometrika Suatu Pendekatan Aplikeasi (Jakarta: PT. Bumi Aksara, 2004).

23 Imam Ghozali, Aplikasi Analisis Multivariate Dengan Program IBM Dan SPSS 21 (Edisi Tujub), Semarang: Universitas Diponegoro, 2013 <https://doi.org/10.1126/science.1158668>. 
Untuk mengetahui ada atau tidaknya multikolinearitas dilakukan dengan menggunakan Variance Inflation Factor (VIF) dengan dasar pengambilan keputusan yaitu jika: a) nilai $\mathrm{VIF} \geq$ atau nilai tolerance $\leq 0,10$ maka terdapat korelasi yang terlalu besar diantara salah satu variabel independen dengan variabel independen yang lain (terjadi multikolinearitas), b) nilai VIF < 10,00 atau nilai tolerance $>0,10$ maka tidak terjadi multikolinearitas, hal ini akan dijelaskan sebagai berikut:

\section{Tabel 10}

\section{Hasil Uji Multikolinearitas}

\begin{tabular}{|c|c|c|c|c|c|c|c|c|}
\hline \multirow[b]{2}{*}{ Hodel } & & \multicolumn{2}{|c|}{$\begin{array}{l}\text { Unstandarcilized } \\
\text { Coefficients }\end{array}$} & \multirow{2}{*}{$\begin{array}{c}\text { Standardized } \\
\text { Coefficients } \\
\text { Beta } \\
\end{array}$} & \multirow[b]{2}{*}{ t } & \multirow[b]{2}{*}{ Sig. } & \multicolumn{2}{|c|}{ Collinearity Statistics } \\
\hline & & B & Stot. Error & & & & Tolerance & VIF \\
\hline 1 & (Constant) & 2,425 & 5,164 & & .470 & .642 & & \\
\hline & $\begin{array}{l}\text { Islamic_Human_Capital } \\
\text { (X1) }\end{array}$ & .508 & ,117 & .673 & 4,325 &, 000 & .837 & 1,195 \\
\hline & $\begin{array}{l}\text { Pengembanngan__Karir } \\
\text { (X2) }\end{array}$ & 067 & 123 & .085 & .547 & 589 & .837 & 1,195 \\
\hline
\end{tabular}

a. DependentVariable: Kinerja_Karjawan (Y)

Sumber: Data diolah dengan SPSS, 2019

Berdasarkan tabel di atas menjelaskan bahwa nilai tolerance pada variable Islamic Human Capital (X1) dan Pengembangan Karir (X2) adalah 0,837 lebih besar dari 0,10. Sementara, nilai VIF untuk variabel Islamic Human Capital (X1) dan Pengembangan Karir (X2) adalah 1,195< 10,00. Maka mengacu pada dasar pengambilan keputusan dalam uji Multikolinearitas dapat disimpulkan bahwa tidak terjadi gejala Multikolinearitas dalam model regresi.

\section{Analisis Regresi Linear Berganda (Multiples)}

Adapun hasil regresi linier berganda pengaruh islamic buman capital dan pengembangan karir terhadap kinerja karyawan Bank Syariah di Kabupaten Pasaman, adalah sebagai berikut:

\section{Tabel 11}

Hasil Analsis Regresi Linear Berganda

\begin{tabular}{|c|c|c|c|c|c|c|}
\hline \multirow[b]{2}{*}{ Model } & & \multicolumn{2}{|c|}{$\begin{array}{l}\text { Unstandardized } \\
\text { Coefficients }\end{array}$} & \multirow{2}{*}{$\begin{array}{c}\begin{array}{c}\text { Standardized } \\
\text { Coefficients }\end{array} \\
\text { Beta }\end{array}$} & \multirow[b]{2}{*}{$t$} & \multirow[b]{2}{*}{ Sig. } \\
\hline & & B & Std. Error & & & \\
\hline \multirow[t]{3}{*}{1} & (Constant) & 2,425 & 5,164 & & .470 &, 642 \\
\hline & $\begin{array}{l}\text { Islamic_Human_Capital } \\
\text { (X1) }\end{array}$ & .508 & ,117 &, 673 & 4,325 &, 000 \\
\hline & $\begin{array}{l}\text { Pengembangan_Karii } \\
(X 2)\end{array}$ & -067 &, 123 & -085 &,- 547 &, 589 \\
\hline
\end{tabular}

a. Dependent Variable: Kinerja_Karyawan (Y)

Sumber: Data diolah dengan SPSS, 2019
Dari tabel di atas dapat dirumuskan suatu persamaan regresi untuk mengetahui pengaruh islamic buman capital dan pengembangan karir terhadap kinerja karyawan Bank Syariah di Kabupaten Pasaman adalah sebagai berikut:

\section{$\mathrm{Y}=2,425+0,508 \mathrm{X} 1-0,067 \mathrm{X} 2$}

Berdasarkan persamaan diatas, maka dapat diinterpretasikan sebagai berikut:

1. Koefisien-koefisien persamaan regresi linier berganda di atas dapat diartikan koefisien regresi untuk konstan sebesar 2,425menunjukkan bahwa jika variabel islamic human capital dan pengembangan karir bernilai nol maka nilai daya saing meningkat sebesar 2,425satuan atau $24,25 \%$.

2. Variabel islamic buman capital 0,508 menunjukkan bahwa jika variabel islamic buman capital meningkat 1 satuan maka akan meningkatkan kinerja karyawan sebesar 0,508satuan atau 50,8\%, dengan catatan variabel lain dianggap konstan. Berdasarkan tabel di atas variabel islamic buman capital berpengaruh positif terhadap kinerja karyawan Bank Syariah di Kabupaten Pasaman, artinya semakin besar kualitas islamic buman capital, maka kinerja karyawan Bank Syariah di Kabupaten Pasaman akan meningkat.

3. Variabel pengembangan karir0,067menunjukkan bahwa jika variabel pengembangan karir meningkat 1 satuan maka akan meningkatkan kinerja karyawan sebesar $-0,067$ satuan atau $-6,7 \%$, dengan catatan variabel lain dianggap konstan. Berdasarkan tabel di atas variabel pengembangan karir berpengaruh negatif terhadap kinerja karyawan Bank Syariah di Kabupaten Pasaman, artinya semakin besar pengembangan karir karyawan Bank Syariah di Kabupaten Pasaman, maka tidak ada penambahan konstan terhadap kinerja karyawan.

\section{Uji Korelasi Linear Berganda (R) dan Koefisien Determinasi $\left(\mathbf{R}^{2}\right)$}

Berdasarkan hasil perhitungan korelasi linear berganda melalui program komputer yaitu SPSS for windows versi 21 diperoleh nilai 
koefisien korelasi (R) dan koefisien determinasi $\left(\mathrm{R}^{2}\right)$ adalahsebagai berikut:

\section{Tabel 12}

\section{Hasil Perhitungan Korelasi Linear Berganda dan Determinasi \\ Model Summary}

\begin{tabular}{|l|r|r|r|r|}
\hline Model & R & R Square & $\begin{array}{c}\text { Adjusted } \\
\text { R Square }\end{array}$ & $\begin{array}{r}\text { Std. Error of } \\
\text { the Estimate }\end{array}$ \\
\hline 1 &, $643^{\circ}$ &, 413 &, 373 & 2,403 \\
\hline
\end{tabular}
a. Predictors: (Constant), Pengembangan_Karir $(X 2)$,
Islamic_Human_Capital (X1)

Sumber: Data diolah dengan SPSS, 2019

Berdasarkan data diatas, maka diperoleh nilai koefisien korelasi (R) sebesar 0,643. Hal ini menunjukkan bahwa terdapat pengaruh yang positif dan kuat variabel islamic buman capital dan pengembangan karir terhadap kinerja karyawan bank syariah di Kabupaten Pasaman. Selanjutnya nilai koefisien determinasi $\left(\mathrm{R}^{2}\right)$ sebesar 0,413. Hasil ini menjelaskan bahwa 41,3\% variasi tinggi rendahnya kinerja karyawan bank syariah di Kabupaten Pasaman dipengaruhi oleh variabel islamic buman capital dan pengembangan karir,sedangkan sisanya sebesar $58,7 \%$ dipengaruhi oleh variabel-variabel lain yang tidak digunakan dalam penelitian ini.

\section{Uji t (Secara Parsial)}

Uji t dilakukan untuk melihat ada tidaknya pengaruh variabel-variabel bebas (Islamic Human Capital dan Pengembangan Karir) secara parsial terhadap variabel terikat (Kinerja Karyawan). Hasil pengujian ini adalah sebagai berikut:

\section{Tabel 13}

\section{Hasil Uji t (Parsial)}

\begin{tabular}{|c|c|c|c|c|c|c|}
\hline \multirow[b]{2}{*}{ Model } & & \multicolumn{2}{|c|}{$\begin{array}{l}\text { Unstandardized } \\
\text { Coefficients }\end{array}$} & \multirow{2}{*}{$\begin{array}{c}\text { Standardized } \\
\text { Coefficients } \\
\text { Beta }\end{array}$} & \multirow[b]{2}{*}{ t } & \multirow[b]{2}{*}{ Sig. } \\
\hline & & B & Std. Error & & & \\
\hline \multirow[t]{3}{*}{1} & (Constant) & 2,425 & 5,164 & & .470 &, 642 \\
\hline & $\begin{array}{l}\text { Islamic_Human_Capital } \\
\text { (X1) }\end{array}$ &, 508 & 117 & .673 & 4,325 & .000 \\
\hline & $\begin{array}{l}\text { Pengembangan_Karir } \\
\text { (X2) }\end{array}$ & -067 &, 123 & -085 & -.547 & .589 \\
\hline
\end{tabular}

Sumber: Data diolah dengan SPSS, 2019

1. Variabel Islamic Human Capital (X1)

a. Merumuskan hipotesis

$\mathrm{H}_{\mathrm{O}}$ : Islamic Human Capital tidak berpengaruh positif terhadap kinerja karyawan.
$\mathrm{H}_{\mathrm{A}}$ : Islamic Human Capital berpengaruh positif terhadap kinerja karyawan.

b. Menentukan levelofsignificance $(\alpha)$

Taraf signifikansi menggunakan $\alpha=5 \%$ atau 0,05

c. Kriteria Pengambilan keputusan

$\mathrm{H}_{\mathrm{O}}$ diterima jika Pvalue (sig) $>\alpha$ $(0,05)$

$\mathrm{H}_{\mathrm{O}}$ ditolak jika Pvalue (sig) $\leq \alpha$ $(0,05)$

d. Kesimpulan

Berdasarkan hasil perhitungan menggunakan SPSS 21 yang tertera pada Tabel 27, diperoleh nilai Pvalue (sig) untuk islamic human capital sebesar 0,000. Diketahui Pvalue (sig) sebesar $0,000<\alpha(0,05)$, maka $\mathrm{H}_{\mathrm{O}}$ ditolak dan $\mathrm{H}_{\mathrm{A}}$ diterima. Jadi dapat disimpulkan bahwa islamic buman capital karyawan Bank syariah di Kabupaten Pasaman berpengaruh positif terhadap kinerja karyawan. Artinya bahwa semakin partisipatif islamic buman capital yang ada dalam perusahaan maka semakin tinggi kinerja karyawan dan sebaliknya dengan tingkat kesalahan 5\%.

2. Variabel Pengembangan $\operatorname{Karir}(\mathrm{X} 2)$

a. Merumuskan hipotesis

$\mathrm{H}_{\mathrm{O}}$ : Pengembangan karir tidak berpengaruh positif terhadap kinerja karyawan.

$\mathrm{H}_{\mathrm{A}}$ : Pengembangan karir berpengaruh positif terhadap kinerja karyawan.

b. Menentukan levelofsignificance $(\alpha)$

Taraf signifikansi menggunakan $\alpha=5 \%$ atau 0,05

c. Kriteria Pengambilan keputusan

$\mathrm{H}_{\mathrm{O}}$ diterima jika Pvalue (sig) $>\alpha$ $(0,05)$

$\mathrm{H}_{\mathrm{O}}$ ditolak jika Pvalue (sig) $\leq \alpha$ $(0,05)$

d. Kesimpulan

Berdasarkan hasil yang tertera pada Tabel 27, diperoleh nilai Pvalue (sig) untuk pengembangan karir sebesar 0,589. Diketahui Pvalue (sig) sebesar $0,589>\alpha(0,05)$, maka $\mathrm{H}_{\mathrm{O}}$ diterima dan 
$\mathrm{H}_{\mathrm{A}}$ ditolak. Jadi dapat disimpulkan bahwa pengembangan karir tidak berpengaruh positif terhadap kinerja karyawan.Artinya bahwa semakin baik pengembangan karir tidak semakin tinggi maupun rendah kinerja karyawan dan sebaliknya dengan tingkat kesalahan 5\%.

\section{Uji F (Secara Simultan)}

Uji F dilakukan untuk menguji signifikansi koefisien regresi seluruh prediktor variabel independen (islamic buman capital dan pengembangan karir) secara bersama-sama terhadap kinerja karyawan. Hasil uji $\mathrm{F}$ sebagai berikut:

\section{Tabel 14}

\section{Hasil Uji F}

\begin{tabular}{|ll|c|r|r|r|c|}
\multicolumn{1}{|c|}{ ANOVA $^{\text {b }}$} \\
Model & & $\begin{array}{c}\text { Sum of } \\
\text { Squares }\end{array}$ & df & Mean Square & F & Sig. \\
\hline 1 & Regression & 117,998 & 2 & 58,999 & 10,217 &, $000^{\text {a }}$ \\
& Residual & 167,470 & 29 & 5,775 & & \\
& Total & 285,469 & 31 & & & \\
\hline
\end{tabular}

a. Predictors: (Constant), Pengembangan_Karir (X2), Islamic_Human_Capital (X1)

b. Dependent Variable: Kinerja_Karyawan ( $Y$ )

Sumber: Data diolah dengan SPSS, 2019

1) Merumuskan hipotesis

$\mathrm{H}_{\mathrm{O}}$ : Islamic buman capital dan pengembangan karir secara simultan tidak berpengaruh terhadap kinerja karyawan.

$\mathrm{H}_{\mathrm{A}}$ : Islamic buman capital dan pengembangan karir secara simultan berpengaruh terhadap kinerja karyawan.

2) Menentukan level of significance (a)

Taraf signifikansi menggunakan $\alpha=5 \%$ atau 0,05

3) Kriteria pengambilan keputusan

$\mathrm{H}_{\mathrm{O}}$ diterima jika Pvalue (sig) $>\alpha(0,05)$

$\mathrm{H}_{\mathrm{O}}$ ditolak jika Pvalue $(\mathrm{sig}) \leq \alpha(0,05)$

4) Kesimpulan

Berdasarkan perhitungan menggunakan SPSS 21 yang tertera pada Tabel 28, diperoleh nilai Pvalue (sig) sebesar 0,000. Jadi diketahui Pvalue (sig) sebesar 0,000 $<\alpha(0,05)$, maka $\mathrm{H}_{\mathrm{O}}$ ditolak dan $\mathrm{H}_{\mathrm{A}}$ diterima. Jadi dapat disimpulkan bahwa Islamic buman capital dan pengembangan karir secara simultan berpengaruh terhadap kinerja karyawan Bank Syariah di Kabupaten Pasaman.

Penelitian ini berfokus pada pengujian pengaruh Islamic Human Capital (X1) dan
Pengembangan Karir (X2) terhadap kinerja karyawan (Y). Berikut akan dibahas hasil penelitian yang telah penulis dapatkan:

\section{Uji Hipotesis 1 Islamic Human Capital Berpengaruh Positif terhadap Kinerja Karyawan}

Hasil penelitian ini menunjukkan bahwa Islamic Human Capital berpengaruh positif terhadap kinerja karyawan, hal ini berarti Islamic Human Capital dengan indikator kemanusiaan, demokrasi, the right man is the right place,equal pay for equal work, kesatuan arah, kesatuan komando, efisiensi, efektivitas, produktivitas kerja, disiplin, dan wewenang dan tanggung jawab berpengaruh terhadap kinerja karyawan.

Berdasarkan penelitian yang dilakukan penulis, kinerja karyawan dapat dipengaruhi oleh Islamic Human Capital Karena setiap karyawan sebagai sumber daya insani merupakan aset/kekayaan utama perusahaan yang sangat perlu dipelihara serta dikembangkan potensi-potensi yang dimilikinya sehingga dapat menjalankan fungsinya dengan baik dalam dalam bidang yang digelutinya dalam perusahaan. Pengelolaan dalam islamic buman capital yang dilaksanakan secara profesional, mampu menghasilkan sumber daya insani yang dapat bekerja secara efisien, efektif dan produktif.

Pengelolaan sumber daya insani secara profesional ini dimulai sejak perekrutan, seleksi, penglasifikasian, penempatan sesuai dengan kemampuan, penataran/pelatihan dan pengembangan karirnya.Dengan pengelolaan islamic buman capital yang baik, dapat menciptakan lingkungan kerja yang harmonis, membantu dalam penempatan sumber daya insani sesuai dengan kemampuan dan keahliannya akan dapat meningkatan kinerja perusahaan, meningkatkan motivasi kerja, serta akan meningkatkan disiplin kerja, perusahaan mampu menetapkan gaji, upah serta kompensasi lainnya secara adil sesuai dengan jabatan, keahlian, pendidikan dan tanggung jawab. Dengan demikian, produktivitas kerja perusahaan dapat tercapai dan akhirnya kinerja perusahaan dapat ditingkatkan dari waktu ke waktu. 
Hasil penelitian ini sejalan dengan penelitian pengaruh buman capital terhadap kinerja pada karyawan unit simpan pinjam koperasi serba usaha (KSU) Mekar Surya Karanganyar tahun 2016 yang dilakukan oleh Doddy Wahyu Triatmaja menunjukkan dimensi Human Capital (tingkat pendidikan, keterampilan dan pengalaman kerja) baik secara bersama-sama maupun parsial berpengaruh positif dan signifikan terhadap kinerja pada karyawan. Disimpulkan juga bahwa pengalaman kerja adalah variabel yang paling dominan dalam mempengaruhi kinerja karyawan.

\section{Uji Hipotesis 2 Pengembangan Karir Berpengaruh Positif terhadap Kinerja Karyawan}

Hasil penelitian ini menunjukkan bahwa variabel pengembangan karir secara parsial tidak mempengaruhi kinerja karyawan bank syariah di Kabupaten Pasaman.Hal ini menunjukkan bahwa pengembangan karir dengan indikator kebijakan organisasi, prestasi kerja, latar belakang pendidikan, pelatihan, pengalaman kerja, dan kesetiaan pada organisasi tidak berpengaruh terhadap kinerja karyawan. Hasil penelitian ini tidak sejalan dengan penelitian yang dilakukan oleh Balbed dan Sintaasih yang menyatakan bahwa kinerja karyawan dapat ditingkatkan dengan menjaga ataupun meningkatkan pengembangan karir dan motivasi kerja karyawan. ${ }^{24}$

Berdasarkan observasi yang dilakukan penulis, penulis menemukan fakta dilapangan bahwa karyawan bank syariah di kabupaten Pasaman bekerja tidak sesuai dengan latar pendidikan yang dimilikinya, beberapa karyawan bank syariah bukan linear berasal dari lulusan perbankan syariah, hal ini mempengaruhi kinerja karyawan dalam pekerjaannya. Selain itu, kebijakan organisasi perusahaan yang kurang memperhitungan kesempatan bagi karyawan untuk mengembangkan karirnya, yang berdampak pada rendahnya motivasi karyawan untuk meningkatkan kinerja dalam

24 Ammar Balbed dan Desak Ketut Sintaasih, Pengaruh Pengembangan Karir Terhadap Kinerja Karyawan Melalui Mediasi Motivasi Kerja Karyawan, Vol.8, No,7, 2019
pekerjaannya.Temuan lainnya adalah mengenai minimnya fasilitas pelatihan diperoleh karyawan dari perusahaan yang berpengaruh terhadap rendahnya kinerja karyawan.

\section{Uji Hipotesis 3 Islamic Human Capital dan Pengembangan Karir Secara Simultan Berpengaruh Terhadap Kinerja Karyawan}

Berdasarkan hasil penelitian yang telah dilakukan, dapat diketahui bahwa variabel islamic human capital dan pengembangan karir secara simultan berpengaruh terhadap kinerja karyawan. Hal tersebut ditunjukkan dari besarnya nilai $\mathrm{F}$ sebesar 10,217 dengan tingkat signifikansi $0,000<0,05$.

Hal tersebut menunjukkan bahwa meskipun dalam penelitian ini pengembangan karir tidak berpengaruh terhadap kinerja karyawan tetapi secara bersama-sama islamic buman capital dan pengembangan karir berpengaruh terhadap kinerja karyawan. Hal itu menunjukkan bahwa islamic buman capital mendukung pengembangan karir dalam meningkatkan kinerja karyawan.

\section{Kesimpulan}

Berdasarkan hasil analisis data islamic buman capital dan pengembangan karir terhadap kinerja karyawan, berikut adalah beberapa kesimpulan dari hasil temuan:

1. Variabel islamic buman capital diperoleh nilai Pvalue (sig) sebesar $0,000<\alpha(0,05)$, maka $\mathrm{H}_{\mathrm{O}}$ ditolak dan $\mathrm{H}_{\mathrm{A}}$ diterima. Maka Variabel islamic buman capital berpengaruh positif dan signifikan terhadap kinerja karyawan.

2. Variabelpengembangan karir diperoleh Pvalue (sig) sebesar 0,589 $>\alpha(0,05)$, maka $\mathrm{H}_{\mathrm{O}}$ diterima dan $\mathrm{H}_{\mathrm{A}}$ ditolak.Maka variabel pengembangan karir tidak berpengaruh positif dan signifikan terhadap kinerja karyawan.

3. Variabel Islamic buman capital dan pengembangan karir diketahui Pvalue (sig) sebesar $0,000<\alpha(0,05)$, maka $\mathrm{H}_{\mathrm{O}}$ ditolak dan $\mathrm{H}_{\mathrm{A}}$ diterima. Maka variabel Islamic buman capital dan pengembangan karir secara simultan berpengaruh terhadap kinerja karyawan. 


\section{Daftar Pustaka}

Abu Fahmi, dkk, Syariah: Teori Dan Implementasi (Jakarta: PT. Gramedia Pustaka Utama, 2014)

Aisyah, Yana, and Jaka Isgiyarta, 'Analisis Pengaruh Human Capital Terhadap Kualitas Auditor (Studi Empiris Pada Bank Bri Kantor Inspeksi Semarang)', Diponegoro Journal of Accounting, 3.2 (2014), 1038-47

Amstrong, Michael, and Angela Baron, Performance Management, Performance Management. London: Institute of Personnel and Development (London: Institute of Personnel and Development., 1998)

Arifin, M, and Hesi Eka Puteri, 'Personality, Grit and Organizational Citizenship Behavior at Vocational Higher Education: The Mediating Role of Job Involvement', Journal of Social Studies Education Research, 10.2 (2019), 168-87

Arikunto, Suharsimi, Prosedur Penelitian Ilmiah (Jakarta: rineka cipta, 2010)

Burhanuddin Yusuf dan M. Nuryanto Al-Arif, Manajemen Sumber Daya Manusia Di Lembaga Keuangan Syariah, (Jakarta: PT. Raja Grafindo Persada, 2015)

Fahmi, Irham, Manajemen Kinerja (Bandung: alfabet, 2010)

Fatihudin, Didin, 'Metodologi Penelitian Untuk Ilmu Ekonomi, Manajemen Dan Akuntansi: Dari Teori Ke Praktek' (Zifatama Publishing, 2015)

Firdaus, Muhammad, Ekonometrika Suatu Pendekatan Aplikasi (Jakarta: PT. Bumi Aksara, 2004)

Ghozali, Imam, Aplikasi Analisis Multivariate Dengan Program IBM Dan SPSS 21 (Edisi Tujuh), Semarang: Universitas Diponegoro, 2013

$<$ https://doi.org/10.1126/science.11586 $68>$

Handoko, Hani, Manajemen Personalia Dan Sumber Daya Manusia, edisi 2 (Yogyakarta: BPFE, 2014)

Kojo, Abrian Imanuel, Paulus Kindangen, and
Yantje Uhing, 'Pengaruh Manajemen Perubahan, Budaya Organisasi Dan Keterlibatan Kerja Terhadap Kinerja Pada PT. Bank Sulut Go', Jurnal EMBA: Jurnal Riset Ekonomi, Manajemen, Bisnis Dan Akuntansi, 7.3 (2019)

Kuncoro Mudrajad, Metode Riset Untuk Bisnis Dan Ekonomi, edisi 4 (jakarta: erlangga)

Marwansyah, Manajemen Sumber Daya Manusia Edisi 2. Bandung: Alfabeta, 2010) (Bandung: Alfabeta, 2010)

Mudrajad, Kuncoro, 'Metode Riset Untuk Bisnis Dan Ekonomi', Jakarta: Erlangga, 2003

Nasfi, Nasfi, Rahmad Rahmad, and Sabri Sabri, 'Pengaruh Kualitas Pelayanan Terhadap Kepuasan Nasabah Perbankan Syariah', EKONOMIKA SYARIAH: Journal of Economic Studies, 4.1 (2020), 1938

Nawaz, Tasawar, 'Intellectual Capital, Financial Crisis and Performance of Islamic Banks: Does Shariah Governance Matter?', International Journal of Business and Society, 18.1 (2017), 211-26

Noor, Dr. Juliansyah, 'Metodologi Penelitian: Skripsi, Tesis, Disertasi, \& Karya Ilmiah', in Metodologi Penelitian: Skripsi, Tesis, Disertasi, \& Karya Ilmiah, 2011

Parerung, A, 'Disiplin, Kompensasi Dan Pengembangan Karir Pengaruhnya Terhadap Kinerja Pada Badan Lingkungan Hidup Provinsi Sulawesi Selatan', EMBA, 2.4 (2014)

Petty, Richard, and James Guthrie, 'Intellectual Capital Literature Review', Journal of Intellectual Capital, 2000

Puteri, Hesi Eka, and M Arifin, 'Exploring Personality, Grit and Organizational Citizenship Behavior at Higher Education: The Mediating Roles Of Job Involvement Exploring Personality, Grit, and Organizational Citizenship Behavior at Higher Education: The Mediating Roles Of Job Involve', Journal of Physics: Conference Series, 1471.1 (2020), 12025 <https://doi.org/10.1088/1742-

Analisis Pengaruh Islamic.... 
EKONOMIKA SYARIAH:

Journal of Economic Studies

6596/1471/1/012025>

Ratnasari, Sri Langgeng, M M SE, and Yenni

Hartati, Manajemen Kinerja Dalam

Organisasi (Penerbit Qiara Media, 2019)

Rivai, Veithzal, and Deddy Mulyadi, Kepemimpinan Dan Perilaku Organisasi (jakarta: rajawali press, 2008)

-, Kepemimpinan Dan Perilaku Organisasi (Edisi Kedua)', Jakarta: PT. Raja Grafindo Persada, 2008

Robbins, Stephen P, and Timothy A Judge, 'Perilaku Organisasi', Edisi Kesepuluh. Jakarta: PT Indeks Kelompok Gramedia, 2006

Sawarjuwono, T., dan A. P. Kadir, 'Intellectual Capital: Perlakuan, Pengukuran Dan Pelaporan. Jurnal Akuntansi Dan Keuangan', Jurnal Akuntansi Dan Keuangan, v0l.5 (2003), 35-57

Sinambela, Lijan P, Kinerja Pegawai Teori Pengukuran Dan Implikasi (Yogyakarta: Graha Ilmu, 2012)

Sudaryono, Pengantar Bisnis Teori Dan Contoh Kasus, (Jakarta: CV. Andi Offset, 2015)

totanan, c, 'Peranan Intellectual Capital Dalam Penciptaan Nilai Untuk Keunggulan Bersaing.', in N0.1, 2004, pp. 27-31

Utaminingsih, Alifiulahtin, Perilaku Organisasi: Kajian Teoritik \& Empirik Terbadap Budaya Organisasi, Gaya Kepemimpinan, Kepercayaan Dan Komitmen (Universitas Brawijaya Press, 2014)

Zhang, Suchuan, 'Impact of Job Involvement on Organizational Citizenship Behaviors in China', J Bus Ethics, 120, 2014, 165-74 <https://doi.org/10.1007/s10551-0131654-x> 